\title{
Assessment of high-sensitivity C-reactive protein tests for the diagnosis of hepatocellular carcinoma in patients with hepatitis B-associated liver cirrhosis
}

\author{
LI-NA MA ${ }^{1 *}$, XIAO-YAN LIU ${ }^{1 *}$, ZHEN-HUI LU ${ }^{2 *}$, LI-GANG WU $^{3 *}$, YUAN-YUAN TANG $^{1 *}$, XIA LUO $^{1 *}$, \\ YAN-CHAO HU $^{1 *}$, TING-TING YAN ${ }^{4 *}$, QI WANG ${ }^{2}$, XIANG-CHUN DING $^{1}$ and YAN XIE ${ }^{5,6}$
}

Departments of ${ }^{1}$ Infectious Disease, ${ }^{2}$ Hepatobiliary Surgery and ${ }^{3}$ Oncological Surgery, General Hospital of Ningxia Medical University; ${ }^{4}$ Clinical Medical College, Ningxia Medical University; ${ }^{5}$ Tissue Organ Bank \& Tissue Engineering Centre, General Hospital of Ningxia Medical University, Yinchuan, Ningxia 750004, P.R. China;

${ }^{6}$ Tissue Repair and Regeneration Program, Institute of Health and Biomedical Innovation, Queensland University of Technology, Kelvin Grove, QLD 4059, Australia

Received June 5, 2015; Accepted February 27, 2017

DOI: $10.3892 / 01.2017 .5890$

\begin{abstract}
Hepatocellular carcinoma (HCC) is a common malignant tumor worldwide, with high morbidity and mortality. Chronic infection with hepatitis B virus (HBV) is a major risk factor for the development of hepatocellular carcinoma and the majority $(\sim 80 \%)$ of hepatocellular carcinoma patients in China exhibit co-morbidity with HBV-associated liver cirrhosis. The goal of reliable early diagnostic and prognostic techniques for HBV-associated HCC remains unrealized. The aim of the present study was to explore the efficacy of serum high-sensitivity C-reactive protein (hs-CRP) tests in the early diagnosis of $\mathrm{HCC}$ in patients with $\mathrm{HBV}$-associated liver cirrhosis. A cohort of 493 patients with $\mathrm{HBV}$-associated liver disease was divided into three groups: Chronic HBV (CHB) group; liver cirrhosis without HCC (LC) group; and liver cirrhosis with HCC (HCC) group. A further 47 healthy individuals comprised the healthy control $(\mathrm{CN})$ group. Comparative analyses of clinical symptoms, histopathology, ultrasound imagery, computed tomography, magnetic resonance imaging, biochemistry [ $\alpha$-fetoprotein (AFP) and liver function enzymes], and hs-CRP tests were conducted across these four groups. Immunohistochemical analysis showed
\end{abstract}

Correspondence to: Dr Xiang-Chun Ding, Department of Infectious Disease, General Hospital of Ningxia Medical University, 804 Shengli Street, Yinchuan, Ningxia 750004, P.R. China E-mail: 13619511768@163.com

*Contributed equally

Abbreviations: HCC, hepatocellular carcinoma; HBV, hepatitis B virus; $\mathrm{CRP}$, C-reactive protein; $\mathrm{CHB}$, chronic hepatitis B virus

Key words: chronic hepatitis B virus, liver cirrhosis, hepatocellular carcinoma, $\alpha$-fetoprotein, high-sensitivity C-reactive protein that CRP is strongly expressed in HCC tumor tissue, but is not expressed elsewhere. Analyses of the correlations between serum hs-CRP levels and HCC clinical parameters indicated that there was no correlation between serum hs-CRP levels, tumor Edmondson grade, tumor-node-metastasis stage and AFP status. Serum hs-CRP and AFP levels were found to be significantly elevated in the HCC group compared to those in the $\mathrm{LC}, \mathrm{CHB}$ and $\mathrm{CN}$ groups $(\mathrm{P}<0.01)$. Receiver operator characteristic analysis showed that measurement of serum hs-CRP could differentiate HCC from HBV-associated liver cirrhosis, as well as increase the accuracy of HCC diagnoses. Additionally, measurement of hs-CRP and AFP together improved diagnostic accuracy for HCC compared with either test alone. Serum hs-CRP could have potential as an effective diagnostic tool to complement AFP in diagnosing HCC and improving the identification of AFP-negative HCC in patients with $\mathrm{HBV}$-associated liver cirrhosis. The present findings may facilitate the earlier diagnosis of hepatocellular carcinoma, permitting more effective treatment and a broader spectrum of treatment modalities for patients with advanced hepatic disease.

\section{Introduction}

Hepatocellular carcinoma (HCC) is a common malignant tumor, with high morbidity and mortality, which affects patients worldwide. Approximately 564,000 novel cases of HCC are diagnosed each year $(1,2)$. HCC is particularly common in Asia due to a high prevalence of chronic hepatitis $\mathrm{B}$ virus (HBV) and hepatitis $\mathrm{C}$ virus (HCV) infections. In China, $\mathrm{HCC}$ has been the second-leading cause of cancer-associated mortalities since the 1990s (3). The majority of HCC patients in China $(\sim 80 \%)$ have co-morbid cirrhosis associated with chronic HBV infection $(4,5)$. The paucity of methods for the early diagnosis of HCC results in a high mortality rate (6-9). The mean 5-year survival rate of advanced liver cancer is $3-5 \%(10,11)$. Although a combination of $\alpha$-fetoprotein (AFP) assays with ultrasound examination is used for early diagnosis 
of liver cancer, only one-third of patients are accurately diagnosed and treated at an early stage of the disease (7). Accordingly, identifying more effective alternative methods for the early diagnosis of hepatocellular carcinoma in patients with HBV-associated liver cirrhosis is imperative.

HCC with HBV-associated liver cirrhosis is usually diagnosed through a combination of patient medical history, physical examination, imaging (ultrasound, MRI or CT scans showing a liver mass consistent with HCC), and optionally, elevated serum AFP level (>400 ng/ml). A suspicious lesion on the sonogram generally requires additional imaging studies to confirm the stage of the tumor, while their sensitivity in detecting small nodules may be low. The addition of arterial phase imaging to conventional CT scanning increases the number of tumor nodules detected, but in nodular cirrhotic livers, detecting HCC is more challenging. While the overall sensitivity of MRI is similar to that of triphasic CT scans, in patients with nodular cirrhotic livers MRI has better sensitivity and specificity. Confirmation of the diagnosis is made by fine needle aspiration or biopsy. Elevation of AFP $>400 \mathrm{ng} / \mathrm{ml}$ can be used instead of fine needle cytology for diagnosis of HCC in patients with liver cirrhosis and a focal hypervascular liver lesion $(>2 \mathrm{~cm})$ in at least one imaging technique. Patients with potentially resectable liver mass and AFP $>400 \mathrm{ng} / \mathrm{ml}$ should undergo surgery without pre-operative fine needle aspiration cytology or biopsy. Any deterioration in liver function in a patient with known liver cirrhosis of any etiology should raise a suspicion of HCC. As an increasing number of cirrhotic patients and/or HBV/HCV carriers undergo diagnostic procedures, it is likely that, in a substantial number of patients, classical echosonography will be the initial imaging technique that raises a suspicion of HCC. Subsequently, the size of lesions and the presence or otherwise of cirrhosis may affect the sequencing of tests used to diagnose HCC. Suspect nodules $<1 \mathrm{~cm}$ should be examined with ultrasound at intervals of 3-6 months; nodules between 1 and $2 \mathrm{~cm}$ in a cirrhotic liver should be investigated with at least two dynamic studies (triphasic CT scan, ultrasound, or MRI with contrast). If two techniques show a typical appearance of HCC, the nodule should be interpreted as such; if that is not the case, the lesion should either be biopsied when possible or be extirpated, at the discretion of the physician. Nodules $>2 \mathrm{~cm}$ with a typical feature of HCC found through a dynamic imaging technique, as well as any nodule associated with AFP concentration $>400 \mathrm{ng} / \mathrm{ml}$ or rising AFP on sequential determinations, does not require biopsy, but should be considered as proven HCC, and appropriate treatment should be started (12). The Barcelona Clinic Liver Cancer (BCLC) staging system was used to define tumor stage $(12,13)$.

C-reactive protein (CRP) is a non-specific acute-phase protein synthesized by the liver in response to acute and chronic inflammation, and thus represents a molecular indicator of inflammation, infection, trauma and tissue necrosis (14-18). Previous studies have found that the serum CRP measurement can be applied not only to assess the severity of liver damage and fibrosis in cases of fatty liver and chronic HCV, but also serves as an independent marker of poor prognosis in patients with hepatocellular carcinoma (19-25). Elevated CRP expression has also been detected in cancers of the lung, ovaries, colon and prostate, as well as colorectal cancer and HCC (26-31). Therefore, the present study proposed that serum
CRP has potential as a diagnostic and prognostic biomarker for multiple human cancers, including HCC. However, the usefulness of serum CRP tests in HCC and other cancers remains unknown.

A high-sensitivity CRP (hs-CRP) assay, which gives results in $25 \mathrm{~min}$, quantifies low levels of CRP (as low as $0.04 \mathrm{mg} / \mathrm{l}$ ) using laser nephelometry. This test has been applied to detect CRP. It is not yet known, however, whether the hs-CRP assay can improve diagnostic accuracy for HCC in patients with HBV-associated liver cirrhosis. The present study evaluated whether the hs-CRP assay can improve the diagnostic accuracy of $\mathrm{HCC}$ in patients with cirrhosis associated with HBV. A total of 491 candidates were recruited and analyzed. The present findings may assist clinicians in the earlier diagnosis of hepatocellular carcinoma, in turn resulting in more effective and alternative treatment modalities for patients with advanced hepatic disease.

\section{Materials and methods}

Patients. Ethical approval for the present study was obtained from the Ethics Committee of the General Hospital of Ningxia Medical University (Yinchuan, China) and written informed consent was acquired from the candidates prior to any treatment. A total of 493 cases of patients diagnosed with HBV-associated liver disease between July 2012 and October 2014 were recruited from the Department of Infectious Disease, General Hospital of Ningxia Medical University, (Yinchuan, China). Patients with liver damage due to autoimmune status, metabolism, medication or alcohol intake, and those with acute infection, rheumatoid arthritis, gout, asthma, chronic lung disease, myocardial infarction or stroke, any of which could alter serum CRP levels, were excluded. Patients with portal vein thrombosis were also excluded from the present study. None of the included patients had been treated with any hepatoprotective, anti-fibrotic or anti-viral drugs prior to the serum samples being collected. All the included patients had a complete data set, including a full medical history, HBV markers, serum HBV DNA level, liver function, AFP level, hs-CRP assay, and magnetic resonance imaging (MRI), computed tomography (CT) and ultrasound imagery. Patients, including 47 healthy individuals, were classified into four groups: Chronic HBV (CHB) group; liver cirrhosis without HCC (LC) group; liver cirrhosis with HCC (HCC) group; and healthy control $(\mathrm{CN})$ group. The demographic and clinical/pathological data are summarized in Table I.

CHB was diagnosed according to the clinical practice guidelines criteria laid down by Asian Pacific Association for the Study of the Liver, European Association for the Study of the Liver and American Association for the Study of Liver Diseases (32). LC diagnosis was confirmed by clinical symptoms, diagnostic ultrasound imaging, histopathology of liver biopsy samples, and laboratory diagnosis, including the presence of ascites, enlargement of the caudate lobe, collateral portal-venous anastomoses, portal hypertension, nodular liver contour, splenomegaly and varices (11).

In total, 47 healthy volunteers, who had no history of alcoholism, taking medications (including traditional Chinese medicines) that could damage the liver, or autoimmune or 
metabolic disorders, and whose blood chemistry was normal, acted as a control group.

Patients currently undergoing, or with any history of, treatment with any hepatoprotective, anti-fibrotic, or anti-viral drugs were excluded from the present study. Additionally, patients and healthy volunteers with conditions such as infection, arthritis, gout, asthma, chronic lung disease, myocardial infarction or stroke were excluded.

Measurements. Serum hs-CRP levels were assayed by Ultra ion immuno-turbidmetric detection kit (Shanghai Changzheng Biological Company, Shanghai, China). Serum AFP levels were analyzed with a chemiluminescence immunoassay analyzer detection kit (Shanghai Abbott Pharmaceutical Co., Ltd., Shanghai, China).

Immunohistochemistry (IHC). Liver tissue samples were stained with Masson Trichrome (ab150686; Abcam, Cambridge, UK) and examined by two independent liver pathologists. For CRP staining, samples were cut into 3-5 mm sections, formalin-fixed and embedded in paraffin. The sections were then dewaxed, rehydrated, and incubated in $3 \%$ hydrogen peroxide to quench endogenous peroxidase activity. The samples were incubated with anti-CRP primary antibody (dilution, 1:1,000; bs-0115R; Hotgen Biotech, Beijing, China) and secondary antibody (HRP-labeled anti-rabbit; dilution, 1:5,000; BA1003; BosterBio, Wuhan, China) overnight at $4^{\circ} \mathrm{C}$. Subsequently, 3,3'-Diaminobenzidine Substrate Chromogen System (Dako; Agilent Technologies, Inc., Santa Clara, CA, USA) was used to detect positive staining. Images were captured using an Olympus E520 microscope (Olympus, Tokyo, Japan). Protein expression was semi-quantified as follows: The positive staining intensity was scored according to the number of cells exhibiting cytoplasmic and nuclear staining, using the following classification system: 0 , no staining; 1 , nuclear staining in $<10 \%$ of cells and/or weak cytoplasmic staining; 2 , nuclear staining in $10-50 \%$ of cells and/or distinct cytoplasmic staining; and 3, nuclear staining in $>50 \%$ of cells and/or strong cytoplasmic staining. The positive staining intensity (scale $0-3$ ) and the percentage of positive cells (0-100\%) were determined and multiplied to produce a final score (0-300). The same experienced pathologists analyzed the IHC data to maintain consistency.

Statistical analysis. Statistical analyses were performed using the SPSS v17.0 software package (SPSS Inc., Chicago, IL, USA). Quantitative data is expressed as the mean \pm standard deviation. The differences between abnormally distributed data were compared using a Wilcoxon rank-sum test, while means from normally distributed data were compared using Student's $t$-test. A $\chi^{2}$ test was used to analyze the count data, while Spearman's rank correlation coefficient was applied to analyze correlation. The area under the curve (AUC) was calculated using receiver operator characteristic (ROC) curve analysis. $\mathrm{P}<0.05$ was considered to indicate a statistically significant difference.

\section{Results}

Baseline demographic and clinical characteristics. A total of 493 cases of previously untreated patients with HBV-associated cirrhosis were recruited into the present study. The patients were classified into CHB (137 cases, 27.79\%), LC (169 cases, $34.28 \%$ ) and HCC (187 cases, 37.93\%) groups. An additional 47 healthy volunteers were recruited as an age-matched control group (Table I).

CRP expression in human tissues. To further validate CRP expression in HCC and non-tumor liver tissues in patients, immunohistochemical analysis was employed to detect the presence of CRP in 126 cases of non-tumor tissue samples and 134 cases of HCC tissue samples. IHC analysis showed that CRP is abundantly expressed in HCC tissues, but not in non-tumor tissues. CRP-positive staining was mainly found in parenchymal cells, but several non-parenchymal cells also showed positive staining of CRP (Fig. 1). Staining defined as 'negative', 'weak positive', 'moderate positive' and 'strong positive' was found in 21.43, 33.33, 25.40 and 19.18\%, and $7.46,4.48,41.79$ and $46.27 \%$ of non-tumor and HCC tissue samples, respectively. In addition, the total positive rates of CRP expression in non-tumor and HCC tissues samples were 78.57 and $92.54 \%$, respectively (Table II). Additionally, IHC scores for CRP were significantly increased in tumor tissue samples (64.04 \pm 91.52$)$ compared with non-tumor tissue samples $(21.40 \pm 38.72)(\mathrm{P}<0.05$; Table II).

Serum hs-CRP and AFP levels. Serum hs-CRP and AFP levels were found to be significantly elevated in the HCC group compared to those in the $\mathrm{LC}, \mathrm{CHB}$ and $\mathrm{CN}$ groups $(\mathrm{P}<0.01)$. The mean levels of hs-CRP and AFP in the HCC group $(17.34 \pm 22.61$ and $492.61 \pm 544.15 \mathrm{ng} / \mathrm{ml})$ were significantly increased with the levels in the LC $(2.83 \pm 3.05$ and $104.08 \pm 186.3 \mathrm{~nm} / \mathrm{l}), \mathrm{CHB}(1.53 \pm 2.7$ and $16.15 \pm 43.35 \mathrm{ng} / \mathrm{ml})$ and $\mathrm{CN}(0.59 \pm 0.53$ and $4.48 \pm 1.29 \mathrm{ng} / \mathrm{ml})$ groups $(\mathrm{P}<0.05$; Table I).

Correlation between serum hs-CRP level and HCC clinical parameters. The clinical parameters of patients with HCC were AFP, tumor Edmondson grade and tumor-node-metastasis (TNM) stage. The differences among the groups were analyzed by $\chi^{2}$ test. To evaluate clinical relevance, the association between serum hs-CRP concentration and the pathological characteristics of HCC patients were examined. Analysis of the correlation between serum hs-CRP level and HCC clinical parameters indicated that there was no correlation between hs-CRP serum levels and tumor Edmondson grade $(\mathrm{r}=0.238$, $\mathrm{P}=0.229)$, TNM stage $(\mathrm{r}=0.159, \mathrm{P}=0.498)$ or AFP status $(\mathrm{r}=0.336, \mathrm{P}=0.737)$ (Table III).

ROC curve analyses of serum hs-CRP and AFP levels for the diagnosis of HCC. ROC curve analysis was used to clarify the optimal cut-off value of CRP expression in the diagnosis of HCC. The ROC curve showed that the sensitivity and specificity of serum hs-CRP levels for the diagnosis of HCC were 84.16 and $61.59 \%$, respectively [95\% confidence interval (CI), 0.867-0.933], while those of serum AFP for HCC diagnosis were 74.42 and $55.63 \%$, respectively (95\% CI, 0.778-0.864). The AUC of CRP and AFP levels for HCC diagnosis were 0.903 and 0.824 , respectively. The optimal cut-off levels for serum CRP and AFP in the diagnosis of HCC were $2.17 \mathrm{mg} / 1$ and $20 \mathrm{ng} / \mathrm{ml}$, respectively (Fig. 2). ROC analysis showed that 
Table I. Patient demographic and clinical characteristics.

\begin{tabular}{|c|c|c|c|c|}
\hline \multirow[b]{2}{*}{ Characteristic } & \multicolumn{4}{|c|}{ Group } \\
\hline & $\mathrm{HC}$ & CHB & $\mathrm{LC}$ & $\mathrm{HCC}$ \\
\hline Total, $\mathrm{n}$ & 47 & 137 & 169 & 187 \\
\hline Age, mean years \pm SD & $39 \pm 12.1$ & $34 \pm 10.6$ & $46 \pm 10.2$ & $48 \pm 10.6$ \\
\hline Gender ratio, M:F & $39: 8$ & $110: 27$ & $131: 38$ & $144: 43$ \\
\hline \multicolumn{5}{|l|}{ HBeAg status, $n$} \\
\hline HBeAg positive & NA & 87 & 45 & 42 \\
\hline $\mathrm{HBeAg}$ negative & NA & 50 & 124 & 145 \\
\hline HBV DNA, mean $\log I \mathrm{U} / \mathrm{ml} \pm \mathrm{SD}$ & NA & $3.26 \pm 2.25$ & $2.90 \pm 2.72$ & $3.35 \pm 2.71$ \\
\hline $\mathrm{ALT}$, mean IU/1 $\pm \mathrm{SD}$ & $19.80 \pm 13.17$ & $131.33 \pm 181.22$ & $101.78 \pm 177.24$ & $53.64 \pm 66.04$ \\
\hline $\mathrm{AFP}$, mean $\mathrm{ng} / \mathrm{ml} \pm \mathrm{SD}$ & $4.48 \pm 1.29$ & $16.15 \pm 43.35$ & $104.08 \pm 186.30$ & $492.61 \pm 544.00$ \\
\hline \multicolumn{5}{|l|}{ AFP status, $n$} \\
\hline AFP negative & NA & NA & 64 & 65 \\
\hline AFP positive & & & 105 & 122 \\
\hline hs-CRP, mean mg/l \pm SD & $0.59 \pm 0.53$ & $1.53 \pm 2.70$ & $2.83 \pm 3.05$ & $17.34 \pm 22.61$ \\
\hline Child class (A:B:C), \% & NA & NA & $47: 53: 69$ & $52: 75: 60$ \\
\hline MELD score, mean \pm SD & NA & NA & $9.0 \pm 6$ & $11.5 \pm 4$ \\
\hline \multicolumn{5}{|l|}{ TNM stage, $\mathrm{n}$} \\
\hline I-II & NA & NA & NA & 109 \\
\hline III-IV & & & & 78 \\
\hline \multicolumn{5}{|l|}{ Metastasis, $\mathrm{n}$} \\
\hline Yes & NA & NA & NA & 123 \\
\hline No & & & & 64 \\
\hline
\end{tabular}

The diagnostic cutoff values of AFP was $20 \mathrm{ng} / \mathrm{l}$. HCC, hepatocellular carcinoma; CHB, chronic hepatitis B virus; LC, liver cirrhosis; HC, healthy control; AFP, $\alpha$-fetoprotein; MELD, model for end-stage liver disease; ALT, alanine aminotransferase; hs-CRP, high-sensitivity C-reactive protein; AFP, $\alpha$-fetoprotein; HBV DNA, hepatitis B virus deoxyribose nucleic acid; HbeAg, hepatitis B eantigen; NA, not applicable; SD, standard deviation; TNM, tumor-node-metastasis.

Table II. CRP expression in non-tumor and HCC tissue samples.

\begin{tabular}{|c|c|c|c|c|c|c|c|}
\hline \multirow[b]{2}{*}{ Tissue type } & \multirow[b]{2}{*}{$\mathrm{n}$} & \multicolumn{4}{|c|}{ CRP staining intensity, n (\%) } & \multirow{2}{*}{$\begin{array}{l}\text { Total positive } \\
\text { rate, } \%\end{array}$} & \multirow{2}{*}{$\begin{array}{c}\text { CRP staining } \\
\text { score }\end{array}$} \\
\hline & & - & + & ++ & +++ & & \\
\hline Non-tumor & 126 & $27(21.43)$ & $42(33.33)$ & $32(25.40)$ & $25(19.84)$ & 78.57 & $21.40 \pm 38.72$ \\
\hline $\mathrm{HCC}$ & 134 & $10(7.46)$ & $6(4.48)$ & $56(41.79)$ & $62(46.27)$ & 92.54 & $64.04 \pm 91.52$ \\
\hline
\end{tabular}

-, negative; +, weakly positive; ++, moderate positive; +++, strongly positive; CRP, C-reactive protein; HCC, hepatocellular carcinoma.

measurement of serum hs-CRP could differentiate between $\mathrm{HCC}$ and HBV-associated liver cirrhosis and increase the diagnostic accuracy for HCC. Additionally, measurement of hs-CRP and AFP together improved the diagnostic accuracy for HCC compared with all controls and either test alone (Table IV).

Comparison of positive rates of serum CRP and AFP expression. In the present study, $20 \mathrm{ng} / \mathrm{ml} \mathrm{AFP} \mathrm{and} 2.17 \mathrm{mg} / \mathrm{l} \mathrm{hs}-\mathrm{CRP}$ were regarded as the optimal cut-off levels. The results showed that 161 patients $(86.1 \%)$ were positive for CRP, whereas
130 patients $(69.52 \%)$ were positive for AFP (187 patients; $\chi^{2}=14.881 ; \mathrm{P}<0.001$ ) (Table V). The CRP positive rate in HCC patients was increased compared with liver cirrhosis patients $\left(\chi^{2}=93.761 ; \mathrm{P}<0.001\right)$ (Table IV), while the positive rate of AFP in patients with HCC was similar to that in patients with liver cirrhosis $\left(\chi^{2}=2.16 ; \mathrm{P}>0.01\right)$ (Table V). The positive rate of CRP in AFP-positive patients with liver cirrhosis was increased compared with that in AFP-negative patients with liver cirrhosis, while the positive rate of CRP in AFP-positive patients with HCC was similar to that of AFP-negative patients with HCC (Table VI). Overall, these data indicate that 
Table III. Correlation between serum hs-CRP concentration and AFP status, TNM stage and tumor Edmondson grading in hepatocellular carcinoma patients.

\begin{tabular}{lccc}
\hline Parameter & $\mathrm{n}$ & hs-CRP concentration, mg/l & r \\
\hline AFP status & & & 0.336 \\
$\quad$ AFP negative & 65 & $15.51 \pm 22.016$ & 0.737 \\
AFP positive & 122 & $17.24 \pm 22.044$ & 0.238 \\
TNM stage & & & 0.229 \\
I & 40 & $18.24 \pm 19.39$ & $19.37 \pm 21.06$ \\
II & 69 & $20.40 \pm 26.37$ & 0.159 \\
III & 45 & $32.71 \pm 32.41$ & \\
IV & 33 & & 0.498 \\
Edmondson grading & & $19.02 \pm 19.81$ & \\
Early stages (I-II) & 109 & $24.02 \pm 27.82$ & \\
Advanced stages (III-IV) & 78 & & \\
\hline
\end{tabular}

The diagnostic cutoff values of AFP was $20 \mathrm{ng} / \mathrm{l}$. Data are presented as the mean \pm standard deviation. hs-CRP, high-sensitivity C-reactive protein; AFP, $\alpha$-fetoprotein; HCC, hepatocellular carcinoma; TNM, tumor-node-metastasis.

Table IV. Assessment of serum hs-CRP, AFP and CRP+AFP in the diagnosis of hepatocellular carcinoma.

\begin{tabular}{lcccr}
\hline Parameter & AUC & Sensitivity, $\%$ & Specificity, $\%$ & PPV, \% \\
\hline AFP & 0.824 & 74.42 & 55.63 & 51.60 \\
CRP & 0.903 & 84.16 & 61.59 & 59.44 \\
CRP+AFP & 0.998 & 94.06 & 37.75 & 81.36 \\
\hline
\end{tabular}

The diagnostic cutoff values of serum CRP and AFP were $2.17 \mathrm{mg} / \mathrm{l}$ and $20 \mathrm{ng} / \mathrm{l}$, respectively. hs-CRP, high-sensitivity C-reactive protein; AFP, $\alpha$-fetoprotein; AUC, area under the curve; PPV, positive predictive value; NPV, negative predictive value.

Table V. Comparison between the positive rate of serum CRP and AFP expression.

\begin{tabular}{lrcc}
\hline Group & \multicolumn{1}{c}{$\mathrm{n}$} & CRP positive, $\mathrm{n}(\%)$ & AFP positive, $\mathrm{n}(\%)$ \\
\hline HC & 47 & 0 & 0 \\
CHB & 137 & $16(11.68)$ & $17(12.41)$ \\
LC & 169 & $71(42.01)$ & $105(62.13)$ \\
HCC & 187 & $161(86.10)$ & $130(69.52)$ \\
\hline
\end{tabular}

The diagnostic cutoff values of serum CRP and AFP were $2.17 \mathrm{mg} / \mathrm{l}$ and $20 \mathrm{ng} / \mathrm{ml}$, respectively. CRP, C-reactive protein; AFP, $\alpha$-fetoprotein; HCC, hepatocellular carcinoma; CHB, chronic hepatitis B virus; LC, liver cirrhosis; HC, healthy control.

serum hs-CRP measurement can raise the diagnostic accuracy for AFP-negative HCC in patients with HBV-associated liver cirrhosis.

\section{Discussion}

Chronic inflammation has been reported to be involved in tumor initiation, promotion, progression, invasion, and metastasis (33-41). HBV-associated HCC is a typical inflammation-associated malignancy (42-44). CRP is a sensitive acute-phase reactant and a particularly sensitive marker of inflammation and tissue damage in the liver (37-40). At present, several studies have described elevated CRP expression in cancer cells and tissues, including HCC (25-31), but whether CRP expression plays a role in the development or progression of $\mathrm{HBV}$-associated HCC remains unknown. The present study aimed to determine whether CRP is expressed in the tissue of HBV-associated HCC with liver cirrhosis, and whether there is any difference in serum CRP levels between $\mathrm{HBV}$-associated HCC with liver cirrhosis, HBV-associated liver cirrhosis without $\mathrm{HCC}, \mathrm{CHB}$ patients and healthy control subjects. The present study found that CRP is strongly expressed in HCC tissues [including AFP (-) and (+) HCC patients], but not in non-tumor tissues. Additionally, IHC scores for CRP were significantly increased in tumor tissue samples compared with non-tumor tissue samples $(\mathrm{P}<0.05)$. It was also observed that serum CRP levels were significantly increased in patients with HBV-associated HCC compared with patients with $\mathrm{HBV}$-associated liver cirrhosis without $\mathrm{HCC}, \mathrm{CHB}$ patients, and the healthy control group $(\mathrm{P}<0.05)$. On the basis of the aforementioned data, the present study hypothesizes that CRP plays an important role in the development and progression of HCC, and serum CRP level has potential as a diagnostic and prognostic biomarker 
Table VI. Serum hs-CRP positive rate in AFP-negative or AFP-positive patients with liver cirrhosis and HCC.

\begin{tabular}{lrcccr}
\hline Patient group & Total, $\mathrm{n}$ & CRP positive, $\mathrm{n}$ & CRP positive rate, $\%$ & $\chi^{2}$ & P-value \\
\hline LC & 169 & & & 6.422 & 0.011 \\
AFP negative & 64 & 19 & 29.69 & & \\
AFP positive & 105 & 52 & 49.52 & 0.183 & 0.669 \\
HCC & 187 & & & & \\
AFP negative & 65 & 55 & 84.62 & & \\
AFP positive & 122 & 106 & 86.89 & & \\
\hline
\end{tabular}

The diagnostic cutoff values of serum CRP and AFP were $2.17 \mathrm{mg} / \mathrm{l}$ and $20 \mathrm{ng} / \mathrm{l}$, respectively. CRP, C-reactive protein; AFP, $\alpha$-fetoprotein; HCC, hepatocellular carcinoma; LC, liver cirrhosis.

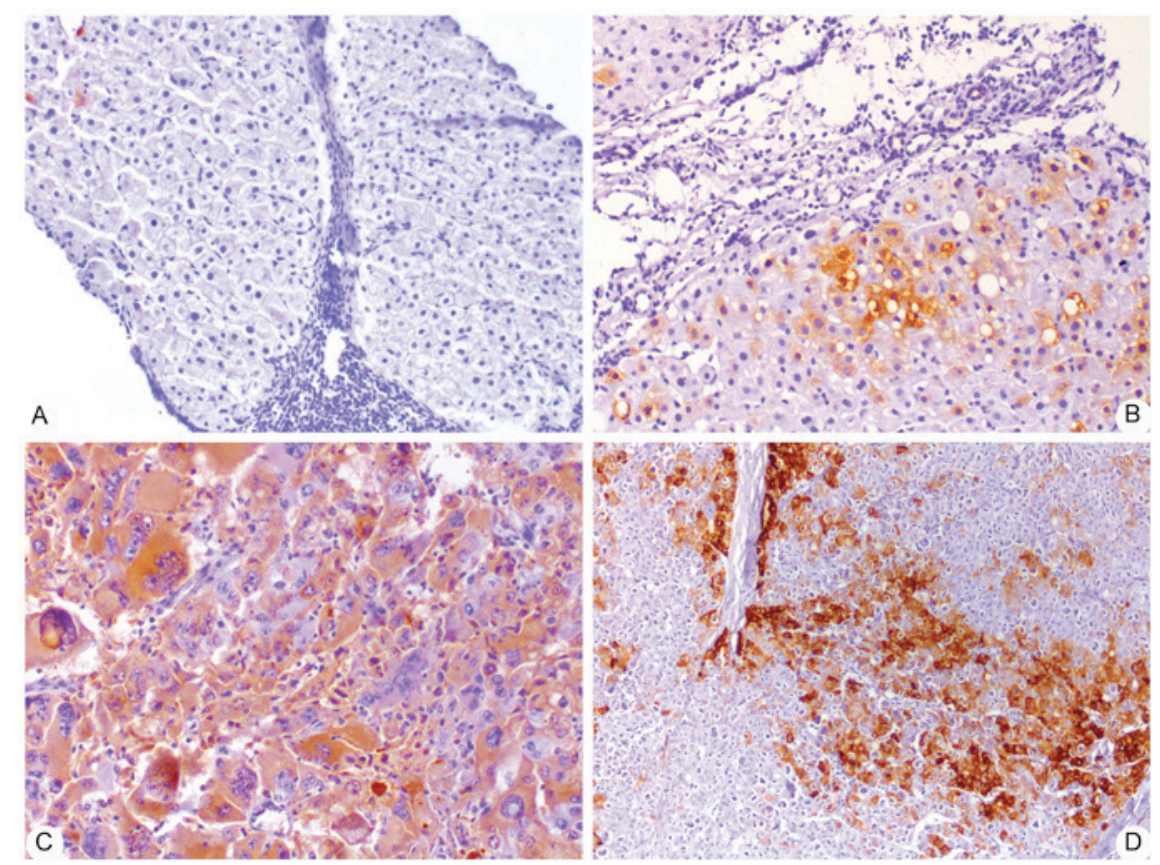

Figure 1. Representative immunohistochemistry images of C-reactive protein in non-tumor and HCC (magnification, x100) tissues, consisting of (A) chronic $\mathrm{HBV}$, (B) HBV-associated liver cirrhosis, (C) AFP-positive HBV-associated HCC and (D) AFP-negative HBV-associated HCC. HCC, hepatocellular carcinoma; HBV, hepatits B virus; AFP, $\alpha$-fetoprotein.

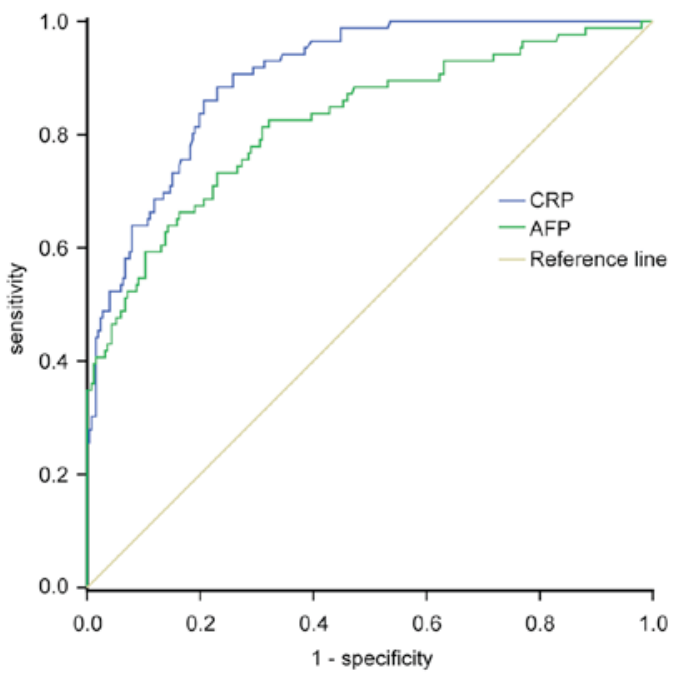

Figure 2. Receiver operating characteristic curve for CRP and AFP in patients with hepatocellular carcinoma compared with the controls. AFP, $\alpha$-fetoprotein; CRP, C-reactive protein. for HCC. However, earlier studies have indicated that serum CRP measurement is not a good diagnostic marker for HCC (21-23). It was found that serum CRP levels in earlier studies were measured with a commercial kit by a nephelometric method, whose lower accuracy limits its diagnostic efficacy.

hs-CRP, an ultra-sensitive detection technology, can accurately detect low concentrations of CRP; however, whether hs-CRP measurement can improve diagnostic accuracy for $\mathrm{HCC}$ in patients with $\mathrm{HBV}$-associated liver cirrhosis remains unknown. To further clarify the optimal cut-off value of CRP for diagnosing $\mathrm{HCC}$ in patients with $\mathrm{HBV}$-associated liver cirrhosis, ROC curve analysis was performed. The results showed that the sensitivity and specificity of serum hs-CRP for HCC diagnosis were 84.16 and $61.59 \%$; those of serum AFP for HCC diagnosis were 74.42 and $55.63 \%$ respectively. The areas under ROC curve of CRP and AFP were 0.903 and 0.824, respectively. The optimal cut-off levels for serum CRP 
and AFP in the diagnosis of $\mathrm{HCC}$ were $2.17 \mathrm{mg} / \mathrm{l}$ and $20 \mathrm{ng} / \mathrm{ml}$, respectively. ROC analysis indicated that measurement of serum hs-CRP could differentiate HCC from HBV-associated liver cirrhosis and increase the diagnostic accuracy for HCC. Additionally, measurement of hs-CRP and AFP together improved the diagnostic accuracy for HCC compared with all controls compared with either test alone.

Since the identification of AFP in the 1970s, AFP has been the only serologic marker widely used in HCC diagnosis. However, its diagnostic power has been continuously questioned and debated. For example, elevated serum AFP was only observed in $60-70 \%$ of HCC patients, while the proportion was just $33-65 \%$ in patients harboring $\mathrm{HCCs}<3 \mathrm{~cm}$ in diameter $(7,8)$. In addition, the non-specific elevation of serum concentrations of AFP may be present in patients with non-malignant chronic liver disease, such as patients with chronic HBV (15-58\%) and patients with liver cirrhosis $(11-47 \%)(7,8,11,28,45)$. Therefore, the efficacy of AFP as a biomarker for HCC diagnosis has been questioned. The development of more effective alternative diagnostic methods to complement AFP is urgently required to improve clinical outcomes. In the present study, $20 \mathrm{ng} / \mathrm{ml}$ AFP and $2.17 \mathrm{mg} / \mathrm{l} \mathrm{hs-CRP}$ were regarded as the optimal cut-off levels for the diagnosis of HCC. The results showed that $86.1 \%$ of HCC patients were positive for CRP, whereas $69.52 \%$ of HCC patients were positive for AFP. The CRP positive rate in HCC patients was increased compared with liver cirrhosis patients, while the positive rate of AFP in patients with HCC was similar to patients with liver cirrhosis. The positive rate of CRP in AFP-positive HCC patients was similar to the rate in AFP-negative HCC patients. These results indicated that serum hs-CRP measurement is able to differentiate between $\mathrm{HCC}$ and $\mathrm{HBV}$-associated liver cirrhosis, and the diagnostic accuracy for AFP-negative HCC with HBV-associated liver cirrhosis was increased. However, the association between $\mathrm{CRP}$ and $\mathrm{HBV}$-associated HCC is more complicated than expected. Serum AFP and CRP are also frequently elevated in patients with chronic $\mathrm{HBV}$ and $\mathrm{HBV}$-associated liver cirrhosis who do not have HCC. Yang et al (46) recently reported that in cases where there is a delayed response in AFP levels to entecavir in patients with elevated AFP levels, this delay acts as an indicator of high HCC risk $(46,47)$. However, the clinical significance of CRP response to antiviral treatments remains to be fully studied. Thus, the diagnostic value of serum CRP level for HCC diagnosis requires additional investigation.

Serum hs-CRP level may be an effective diagnostic metric to complement AFP level in diagnosing $\mathrm{HCC}$ and improving the identification of patients with AFP-negative HCC in cases of HBV-associated liver cirrhosis. The present findings may improve the early diagnosis of hepatocellular carcinoma, permitting more effective and alternative treatment modalities for patients with advanced hepatic disease.

\section{Acknowledgements}

The present study was supported by the National Natural Science Foundation of China (grant no. 81460301), the Natural Science Foundation of Ningxia (grant nos. NZ09115 and NZ11199), the Scientific and Technological Foundation of Ningxia (grant no. NZI5134), and Chinese Foundation for Hepatitis Wang Bao-en Liver Fibrosis Fund (grant no. xjs).

\section{References}

1. El-Serag HB: Epidemiology of viral hepatitis and hepatocellular carcinoma. Gastroenterology 142: 1264-1273.e1, 2012.

2. Luk JM and Liu AM: Proteomics of hepatocellular carcinoma in Chinese patients. OMICS 15: 261-266, 2011.

3. Tang ZY: Hepatocellular carcinoma-cause, treatment and metastasis. World J Gastroenterol 7: 445-454, 2001.

4. Lin CL and Kao JH: Risk stratification for hepatitis B virus related hepatocellular carcinoma. J Gastroenterol Hepatol 28: 10-17, 2013.

5. Gao Y, Jiang Q, Zhou X, Ding B, Wang R, Zhao G and Chen Y: HBV infection and familial aggregation of liver cancer: An analysis of case-control family study. Cancer Causes Control 15: 845-850, 2004.

6. Fu WM, Zhang JF, Wang H, Xi ZC, Wang WM, Zhuang P, Zhu X, Chen SC, Chan TM, Leung KS, et al: Heat shock protein 27 mediates the effect of 1,3,5-trihydroxy-13,13-dimethyl-2H-pyran [7,6-b] xanthone on mitochondrial apoptosis in hepatocellular carcinoma. J Proteomics 75: 4833-4843, 2012.

7. Patel M, Shariff MI, Ladep NG, Thillainayagam AV, Thomas HC, Khan SA and Taylor-Robinson SD: Hepatocellular carcinoma: Diagnostics and screening. J Eval Clin Pract 18: 335-342, 2012

8. Shariff MI, Cox IJ, Gomaa AI, Khan SA, Gedroyc W and Taylor-Robinson SD: Hepatocellular carcinoma: Current trends in worldwide epidemiology, risk factors, diagnosis and therapeutics. Expert Rev Gastroenterol Hepatol 3: 353-367, 2009.

9. Xu C, Lee SA and Chen X: RNA interference as therapeutics for hepatocellular carcinoma. Recent Pat Anticancer Drug Discov 6: 106-115, 2011.

10. Siegel R, Naishadham D and Jemal A: Cancer Statistics, 2013. CA Cancer J Clin 63: 11-30, 2013.

11. Shen Q, Fan J, Yang XR, Tan Y, Zhao W, Xu Y, Wang N, Niu Y, $\mathrm{Wu} \mathrm{Z}$, Zhou J, et al: Serum DKK1 as a protein biomarker for the diagnosis of hepatocellular carcinoma: A large-scale, multicentre study. Lancet Oncol 13: 817-826, 2012.

12. Jelic S and Sotiropoulos GC; ESMO Guidelines Working Group: Hepatocellular carcinoma: ESMO clinical practice guidelines for diagnosis, treatment and follow-up. Ann Oncol 21 (Suppl 5): v59-v64, 2010

13. Llovet JM, Di Bisceglie AM, Bruix J, Kramer BS, Lencioni R, Zhu AX, Sherman M, Schwartz M, Lotze M, Talwalkar J, et al: Design and endpoints of clinical trials in hepatocellular carcinoma. J Natl Cancer Inst 100: 698-711, 2008.

14. Shameem M, Bhargava R, Ahmad Z, Saad T, Fatima N and Malik A: Association between serum C-reactive protein levels and other important predictive markers of outcome in COPD. Acta Med Iran 49: 18-20, 2011.

15. Tanriverdi H, Tor MM, Kart L, Altın R, Atalay F and SumbSümbüloğlu V: Prognostic value of serum procalcitonin and C-reactive protein levels in critically ill patients who developed ventilator-associated pneumonia. Ann Thorac Med 10: 137-142, 2015.

16. Garcia-Rio F, Miravitlles M, Soriano JB, Muñoz L, Duran-Tauleria E, Sánchez G, Sobradillo V and Ancochea J; EPI-SCAN Steering Committee: Systemic inflammation in chronic obstructive pulmonary disease: A population-based study. Respir Res 11: 63, 2010.

17. Abd TT, Eapen DJ, Bajpai A, Goyal A, Dollar A and Sperling L: The role of C-reactive protein as a risk predictor of coronary atherosclerosis: Implications from the JUPITER trial. Curr Atheroscler Rep 13: 154-161, 2011.

18. Peisajovich A, Marnell L, Mold C and Du Clos TW: C reactive protein at the interface between innate immunity and inflammation. Expert Rev Clin Immunol 4: 379-390, 2008.

19. Lin ZY, Wang LY, Yu ML, Chen SC, Chuang WL, Hsieh MY, Tsai JF and Chang WY: Role of serum C-reactive protein as a marker of hepatocellular carcinoma in patients with cirrhosis. J Gastroenterol Hepatol 15: 417-421, 2000.

20. Fabris C, Pirisi M, Soardo G, Falleti E, Pezzetta F, Vitulli D, Toniutto P, Bortolotti N, Gonano F and Bartoli E: Value of serum C-reactive protein measurement in the detection of hepatocellular carcinoma superimposed on liver cirrhosis. J Cancer Res Clin Oncol 120: 229-232, 1994

21. Lee FY, Lee SD, Tsai YT, Wu JC, Lai KH and Lo KJ: Serum C-reactive protein as a serum marker for the diagnosis of hepatocellular carcinoma. Cancer 63: 1567-1571, 1989. 
22. Andreozzi P, Viscogliosi G, Colella F, Subic M, Cipriani E Marigliano B, Verrusio W, Servello A, Ettorre E and Marigliano V: Predictors of liver fibrosis in patients with non-alcoholic fatty liver disease. The role of metabolic syndrome, insulin-resistance and inflammation. Recenti Prog Med 103: 570-574, 2012 (In Italian).

23. Komoriya T, Inoue N, Yoshimune K, Ogawa M, Moriyama M and Kohno $\mathrm{H}$ : Use of a highly sensitive latex reagent with amino acid spacer for determination of $\mathrm{C}$-reactive protein concentration in a variety of liver diseases. J Biosci Bioeng 114: 560-563, 2012.

24. Atta M, Cabral M, Santos G, Paraná R and Atta A: Inflammation biomarkers in chronic hepatitis $\mathrm{C}$ : Association with liver histopathology, HCV genotype and cryoglobulinemia. Inflamm Res 61: 1101-1106, 2012

25. Sjöwall C, Cardell K, Boström EA, Bokarewa MI, Enocsson H, Ekstedt M, Lindvall L, Frydén A and Almer S: High prevalence of autoantibodies to C-reactive protein in patients with chronic hepatitis C infection: Association with liver fibrosis and portal inflammation. Hum Immunol 73: 382-388, 2012

26. Rocha P, Morgan CJ, Templeton AJ, Pond GR, Naik G and Sonpavde G: Prognostic impact of C-reactive protein in metastatic prostate cancer: A systematic review and meta-analysis. Oncol Res Treat 37: 772-776, 2014.

27. Shibutani M, Maeda K, Nagahara H, Ohtani H, Sugano K, Ikeya T, Kimura K, Amano R, Kubo N, Tanaka H, et al: Elevated preoperative serum C-reactive protein levels are associated with poor survival in patients with colorectal cancer. Hepatogastroenterology 61: 2236-2240, 2014

28. Chen W, Wang JB, Abnet CC, Dawsey SM, Fan JH, Yin LY, Yin J, Taylor PR, Qiao YL and Freedman ND: Association between C-reactive protein, incident liver cancer, and chronic liver disease mortality in the Linxian nutrition intervention trials: A nested case-control study. Cancer Epidemiol Biomarkers Prev 24: 386-392, 2015

29. Hefler LA, Concin N, Hofstetter G, Marth C, Mustea A, Sehouli J, Zeillinger R, Leipold H, Lass H, Grimm C, et al: Serum C-reactive protein as independent prognostic variable in patients with ovarian cancer. Clin Cancer Res 14: 710-714, 2008.

30. Xu M, Zhu M, Du Y, Yan B, Wang Q, Wang C and Zhao J: Serum C-reactive protein and risk of lung cancer: A case-control study. Med Oncol 30: 319, 2013.

31. Nozoe T, Matsumata T, Kitamura M and Sugimachi K: Significance of preoperative elevation of serum C-reactive protein as an indicator for prognosis in colorectal cancer. Am J Surg 176: 335-338, 1998.

32. Alberti A and Caporaso N: HBV therapy: Guidelines and open issues. Dig Liv Dis 43 (Suppl 1): S57-S63, 2011.

33. Balkwill $\mathrm{F}$ and Mantovani A: Inflammation and cancer: Back to Virchow? Lancet 357: 539-545, 2001.
34. Okada F: Inflammation-related carcinogenesis: Current findings in epidemiological trends, causes and mechanisms. Yonago Acta Med 57: 65-72, 2014.

35. Feng JF, Huang Y and Chen QX: A new inflammation index is useful for patients with esophageal squamous cell carcinoma. Onco Targets Ther 7: 1811-1815, 2014

36. Nishikawa H, Arimoto A, Wakasa T, Kita R, Kimura T and Osaki Y: Pre-treatment C-reactive protein as a prognostic factor for recurrence after surgical resection of hepatocellular carcinoma. Anticancer Res 33: 1181-1188, 2013.

37. Zhao X, Luo J, Li B, Liu S and Li D: The association between preoperative serum C-reactive protein and hepatocellular carcinoma recurrence in patients with chronic hepatitis $\mathrm{B}$ virus HBV infection-a retrospective study. PLoS One 10: e0116909, 2015.

38. He X, Wang Y, Zhang W, Li H, Luo R, Zhou Y, Liao CL, Huang H, Lv X, Xie Z and He M: Screening differential expression of serum proteins in AFP-negative HBV-related hepatocellular carcinoma using iTRAQ-MALDI-MS/MS. Neoplasma 61: 17-26, 2014.

39. Imai N, Kinoshita A, Onoda H, Iwaku A, Oishi M, Tanaka K, Fushiya N, Koike K, Nishino H and Tajiri H: Persistent elevated $\mathrm{C}$-reactive protein after treatment is an independent marker of a poor prognosis in patients with hepatocellular carcinoma. Clin Transl Oncol 15: 575-581, 2013.

40. Sieghart W, Pinter M, Hucke F, Graziadei I, Schöniger-Hekele M, Müller C, Vogel W, Trauner M and Peck-Radosavljevic M: Single determination of C-reactive protein at the time of diagnosis predicts long-term outcome of patients with hepatocellular carcinoma. Hepatology 57: 2224-2234, 2013.

41. Liu C, Zhang Y, Zhan J, Zhao Y, Wan Q, Peng H and Zhu W: Interleukin-23A is associated with tumor growth in Helicobacter-pylori-related human gastric cancer. Cancer Cell Int 14: 104, 2014

42. Szabo G and Lippai D: Molecular hepatic carcinogenesis: Impact of inflammation. Dig Dis 30: 243-248, 2012.

43. Morales-Sánchez A and Fuentes-Pananá EM: Human Viruses and Cancer. Viruses 6: 4047-4079, 2014.

44. Chen Y, Williams V, Filippova M, Filippov V and Duerksen-Hughes P: Viral carcinogenesis: Factors inducing DNA damage and virus integration. Cancers (Basel) 6: 2155-2186, 2014.

45. Sherman $M$ and Colombo M: Hepatocellular carcinoma screening and diagnosis. Semin Liver Dis 34: 389-397, 2014.

46. Yang SW, Kim GH, Chung JW, Sohn HR, Lee SS, Hong S, Chung SM, Jang ES, Jeong SH and Kim JW: Prediction of risk for hepatocellular carcinoma by response of serum $\alpha$-fetoprotein to entecavir therapy. J Gastroenterol Hepatol 30: 1175-1182, 2015.

47. Triolo M, Della Corte $\mathrm{C}$ and Colombo M: Impact of HBV therapy on the incidence of hepatocellular carcinoma. Liver Int 34 (Suppl 1): S139-S145, 2014. 